\section{POS1171 THE COVID-19 PANDEMIC PROMPTS ISOLATION AND BEHAVIORAL CHANGES IN PATIENTS WITH CHRONIC RHEUMATIC DISEASES LEADING TO REDUCED PHYSICAL ACTIVITY, INCREASED PAIN, DISEASE ACTIVITY, AND LOW SEROPREVALENCE OF SARS- COV2 ANTIBODIES}

C. Ammitzbøll1 ${ }^{1}$, J. B. Andersen ${ }^{1}$, S. R. Vils ${ }^{1,2}$, C. M. Jørgensen ${ }^{1,2,3}$, E. M. Hauge ${ }^{1,3}$, C. Erikstrup ${ }^{3,4}$, S. Mikkelsen ${ }^{3,4}$, M. K. Thomsen ${ }^{5}$, A. Troldborg ${ }^{1,2,3} \cdot{ }^{1}$ Aarhus University Hospital, Rheumatology, Aarhus, Denmark, ${ }^{2}$ Aarhus University, Biomedicine, Aarhus, Denmark; ${ }^{3}$ Aarhus University, Clinical Medicine, Aarhus, Denmark; ${ }^{4}$ Aarhus University Hospital, Clinical Immunology, Aarhus, Denmark; ${ }^{5}$ Aarhus University Hospital, Clinical Microbiology, Aarhus, Denmark

Background: The coronavirus disease 2019 (COVID-19) pandemic has complicated the management of chronic rheumatic diseases (CRD). Patients with CRDs are immunocompromised and generally prone to infection. The fear of COVID-19 and the degree of the self-imposed shielding strategy implemented by many patients introduced new challenges for the patients. Although recommendations have been developed to manage patients with CRDs by, i.e., EULAR, strong evidence is still lacking to guide treatment decisions.

Objectives: This study aimed to assess the seroprevalence of SARS-CoV-2 antibodies in patients with CRDs and healthy controls during the first wave of the pandemic. We further evaluated the effect of the pandemic on patient behavior regarding medication, exercise, pain, and experienced disease activity. Finally, we investigated the self-perceived consequences of the pandemic and lock-down on anxiety and depression in patients with CRDs compared with healthy controls. Methods: More than 900 participants were included in the study: 405 patients with rheumatoid arthritis or systemic lupus erythematosus and 513 blood donors. All participants had SARS-CoV-2 antibodies measured (Wantai SARS-CoV-2 total antibody ELISA; sensitivity $96.7 \%$, specificity $99.5 \%$ ) and answered a questionnaire concerning behavior, anxiety, and symptoms of depression (PHQ-9). The participants with CRD were further asked about physical activity, adherence to medication, and disease-related symptoms.

Results: CRD patients had a sixfold lower seroprevalence of SARS-CoV-2 antibodies compared to controls $(\mathrm{p}=0.03$ ) (Figure 1 ). Almost $60 \%$ of patients were unable to exercise as usual, leading to increased pain in $34 \%$, and experience of increased disease activity in $27 \%$. Approximately $10 \%$ of patients reduced or discontinued their immunosuppressive treatments at their own initiative. Symptoms of moderate depression were present in $19 \%$ of patients compared to $6,8 \%$ of controls $(p<0.001)$.

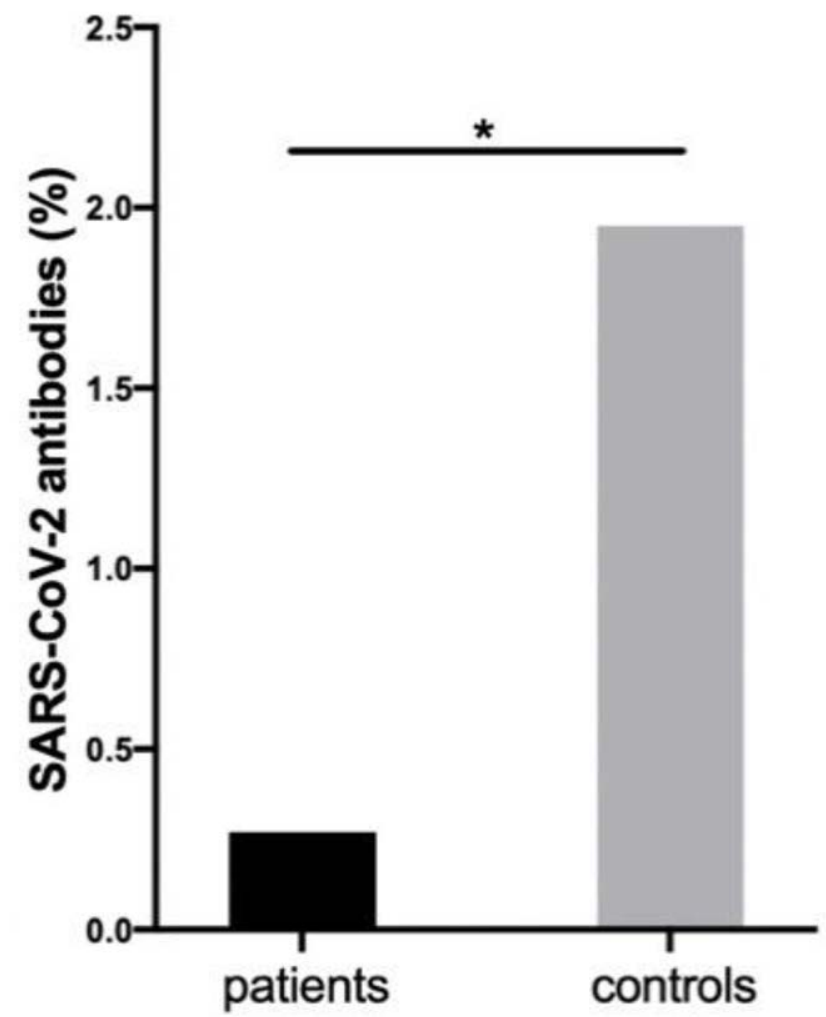

Figure 1. Presence of SARS-CoV-19 antibodies in chronic rheumatic disease patients (1/365, $0.3 \%)$ and controls (blood donors $(10 / 513,1.9 \%)$, ${ }^{*}(p=0.03)$.
Conclusion: Low seroprevalence in patients with CRDs indicates successful mitigation of exposure to SARS-CoV-2. However, this appears to occur at the expense of physical activity and adherence to immunosuppressive treatment Our results raise an important concern regarding the consequences of isolation for patients with CRDs. The result of physical isolation is a risk of severe menta health issues, physical inactivity, self-medication, increased pain, and increased disease activity. The long-term consequences of recommendations for patients with CRDs should be taken into account when tackling the continuing pandemic.

Table 1.

\begin{tabular}{|c|c|c|c|}
\hline Patient characteristics & CRD cohort & \multicolumn{2}{|c|}{ Blood donors } \\
\hline Patients included, $\mathrm{n}$ & 405 (206 SLE, 199 RA) & 513 & \\
\hline Disease duration, years (IQR) & $12.9 \quad(7.0-23.0)$ & & \\
\hline Age, years (IQR) & $(43.6-66.9)$ & 47 & $(33-57)$ \\
\hline $\mathrm{BMI}, \mathrm{kg} / \mathrm{m} 2$ (IQR) & $(22.1-28.6)$ & 25.5 & $(23.1-28.4)$ \\
\hline Charlson Comorbidity Index, score (IQR) & $(1-4)$ & & \\
\hline $\begin{array}{l}\text { Behavioral and mental changes due } \\
\text { to the risk of COVID-19 }\end{array}$ & CRD cohort & $\begin{array}{l}\text { Blood } \\
\text { donors }\end{array}$ & p-value \\
\hline Washes hands more often (\%) & 91.6 & 91.4 & 0.92 \\
\hline Coughing or sneezing in the elbow (\%) & 83.0 & 84.0 & 0.67 \\
\hline Wearing face mask (\%) & 5.0 & 2.4 & 0.001 \\
\hline Restricts the use of public transport (\%) & 47.4 & 32.9 & $<0.001$ \\
\hline $\begin{array}{l}\text { Avoid places where many people are } \\
\text { gathered (\%) }\end{array}$ & 80.7 & 70.0 & $<0.001$ \\
\hline Stay at home $(\%)$ & 51.6 & 35.3 & $<0.001$ \\
\hline $\begin{array}{l}\text { Symptoms of moderate depression, } \\
\text { PHQ- } 9>=10,(\%)\end{array}$ & 19.01 & 6.75 & $<0.001$ \\
\hline $\begin{array}{l}\text { Pandemic effect on training, pain and } \\
\text { disease activity }\end{array}$ & CRD cohort & & \\
\hline $\begin{array}{l}\text { Have you been able to exercise as } \\
\text { usually, yes (\%) }\end{array}$ & 41.4 & & \\
\hline $\begin{array}{l}\text { Have you been less physically active due } \\
\text { to COVID-19, yes (\%) }\end{array}$ & 44.7 & & \\
\hline $\begin{array}{l}\text { Has the degree of physical activity } \\
\text { increased the pain from your rheuma- } \\
\text { tological disease? yes }(\%)\end{array}$ & 33.9 & & \\
\hline $\begin{array}{l}\text { Have you experienced increased disease } \\
\text { activity during COVID-19? yes(\%) }\end{array}$ & 26.9 & & \\
\hline
\end{tabular}

Acknowledgements: This study was funded by the Danish Rheumatism Association. We are thankful for the help with creation of the questionnaire by patient research partners Lene Mandrup Thomsen, Nanna Bacci Hartz, Lene Lau og Jeanette Andersen.

Disclosure of Interests: Christian Ammitzbøll: None declared, Jakob Bøgh Andersen: None declared, Signe Risbøl Vils: None declared, Clara Mistegaard Jørgensen: None declared, Ellen-Margrethe Hauge Speakers bureau: AbbVie, Sanofi, Sobi, MSD, UCB, Grant/research support from: Roche, Norvartis, Christian Erikstrup: None declared, Susan Mikkelsen: None declared, Marianne Kragh Thomsen: None declared, Anne Troldborg: None declared.

DOI: 10.1136/annrheumdis-2021-eular.725

\section{POS1172 COVID-19 ACROSS RHEUMATOLOGY: A} BIBLIOMETRIC STUDY

B. Doskaliuk ${ }^{1}$, R. Yatsyshyn ${ }^{1}$, I. Stoika ${ }^{1}$, K. Fedorovych ${ }^{1}$, O. Drogomeretska ${ }^{1}$ O. Hotsaniuk ${ }^{1}$, Y. Delva ${ }^{1} .{ }^{1} /$ Ivano-Frankivsk National Medical University, Internal medicine \#1 clinical immunology and allergology, Ivano-Frankivsk, Ukraine

Background: The Coronavirus disease 2019 (COVID-19) outbreak spread rapidly among the whole world, becoming the greatest pandemic for the decades. It triggered the enormous challenges for the global health system, forcing doctors and patients to adapt to new realities and the field of rheumatology was not an exclusion.

Objectives: The aim of this study was to analyze articles covering interconnection between COVID-19 and rheumatic diseases; to investigate the common features of papers in this category and indicate the most influential among them; to determine which rheumatic nosologies were most represented.

Methods: For retrieving of literature data, we applied the bibliometric database Scopus and conducted our search on $12^{\text {th }}$ of January using following keywords: "rheumatoid arthritis" OR "systemic lupus erythematosus" OR "systemic sclerosis" OR "vasculitis" OR "myositis" OR "rheumatology" AND "COVID-19". All selected articles were analyzed according to various aspects: type of document authorship, journal, citations score, rheumatology field, country of origin, language, and keywords. We have built the visualizing keywords network (Figure 1) with the help of software tool VOSviewer version 1.6.15 (the minimum keyword occurrence threshold was set at 5). 


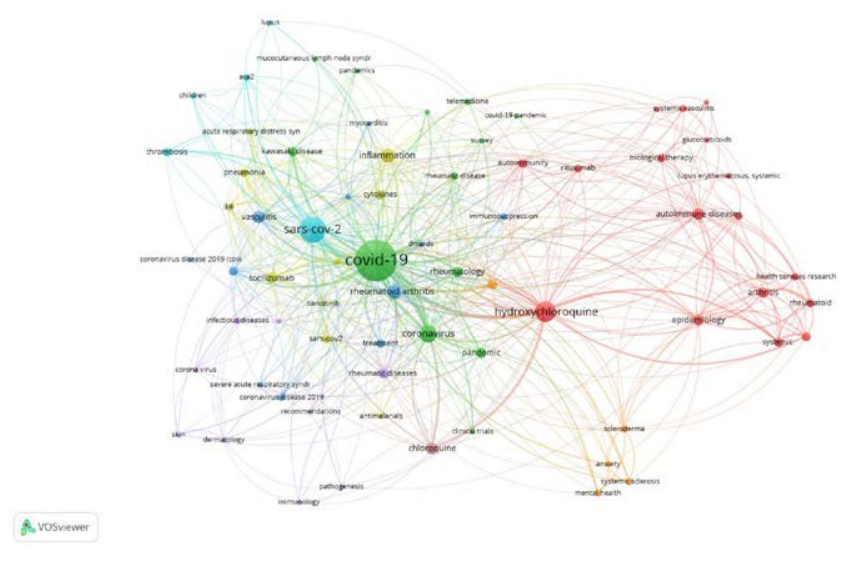

Figure 1.

Results: A total of 844 literature items were obtained. After screening of title, abstract and keywords we excluded 106 records as they were not emphasized the rheumatological perspective on COVID-19 and as a result were inapplicable for this study. The 738 retrieved articles were mostly (86.8\%) open access publications. The top five journals that contributed most to the coverage of this topic were: Annals Of The Rheumatic Diseases $(n=59)$, Clinical Rheumatology $(n=41)$, Lancet Rheumatology $(n=24)$, Arthritis And Rheumatology $(n=20)$ and Rheumatology International $(n=19)$. The origin of most studies was not surprisingly from those countries, which belong to the top ten according to the total cases of COVID-19 [1] (USA - 167; Italy - 148; UK - 76; India - 60 and Spain - 58). Most items were written in English but articles in German $(n=12)$, Spanish $(n=11)$, Russian $(n=5)$ and Chinese $(n=2)$ could also be found. Analyzed studies were designed in the form of Original Articles (41.2\%), Reviews (23.7\%), Letters (21.8), Notes $(6.9 \%)$, Editorials $(5.1 \%)$. According to the citations scores, articles of highest interest were dedicated to clinical course of COVID-19 in patients with autoimmune pathologies. The other highly cited studies were about cytokine storm and perspective usage of biological drugs for severe cases of COVID19. Our analysis of keywords showed that the most widely discussed rheumatic disease in the view of COVID-19 was systemic lupus erythematosus $(n=188)$, followed by vasculitis $(n=132)$, rheumatoid arthritis $(n=90)$, systemic sclerosis $(\mathrm{n}=32)$ and psoriatic arthritis (24). The liveliest discussion about disease-modifying antirheumatic drugs in COVID-19 revolved around hydroxychloroquine $(n=305)$, corticosteroids $(n=161)$, tocilizumab $(n=83)$, methotrexate $(n=46)$ and anakinra $(n=34)$.

Conclusion: As far as we know, it is the first bibliometric overview of studies dedicated to interrelation between COVID-19 and rheumatic pathology. The high number of open access items contributes to the increase of research visibility in this emergently developing research field and facilitates the process of scientific data sharing. The conducting of bibliographic studies may provide a valuable guide through this area of knowledge.

REFERENCES:

[1] https://www.worldometers.info/coronavirus/ Accessed on January 12, 2021

Disclosure of Interests: None declared.

DOI: 10.1136/annrheumdis-2021-eular.734

\section{POS1173 A SHORT DELAY IN ARTHRITIS CARE IS ASSOCIATED WITH HIGHER DISEASE ACTIVITY - LESSONS FROM THE CORONAVIRUS DISEASE 19 (COVID-19) PANDEMIC}

A. Giollo ${ }^{1}$, E. Bertoldo ${ }^{1}$, C. Benini ${ }^{1}$, O. Viapiana ${ }^{1}$, L. Idolazzi ${ }^{1}$, G. Adami ${ }^{1}$ A. Fassio ${ }^{1}$, D. Gatti ${ }^{1}$, M. Rossini ${ }^{1} .{ }^{1}$ University of Verona, Rheumatology Section, Department of Medicine, Verona, Italy

Background: Although disease activity is a significant outcome in rheumatology, few studies have investigated the relationship between routine care of rheumatic conditions and disease activity control.

Objectives: To determine the association between delay in routine care of chronic inflammatory arthritides (CIAs) and disease activity during the first wave of coronavirus disease 19 pandemic in Verona, Italy.

Methods: This study enrolled patients with an established diagnosis of rheumatoid arthritis (RA), psoriatic arthritis (PsA), ankylosing spondylitis (AS) and undifferentiated arthritis (UA). Between 01/04/2020 and 30/06/2020, participants were emailed an online questionnaire. Items comprised multiple or single-choice questions evaluating routine rheumatology care disruptions/delays and disease characteristics, treatments, comorbidities, and demographics. Compliance to anti-rheumatic medications was evaluated with I-CQR5. Disease activity was assessed with RAPID3, and active disease was defined as a RAPID3 score>1. Study period referred to the time between the last rheumatology assessment and the date of enrolment.

Results: Of 1210 patients contacted, 450 participated, of whom $219 \mathrm{CIAs}$ patients were included (RA 55.3\%, PsA 35.2\%, AS 15.1\%, UA 3.7\%). One hundred twenty-five patients $(57.1 \%)$ had their routine clinical assessment delayed (median days 68.4; IQR 66.8, 85.9). Patients in this group had significantly higher MDHAQ $(p=0.001)$ and RAPID3 ( $p=0.031)$ scores, while they did not differ for disease severity, medications or compliance. Most (87.7\%) reported good compliance to therapy; only $5.9 \%$ had difficulties in supplying anti-rheumatic medications, and $13.2 \%$ discontinued medications for at least four weeks for any reason. However, several patients $(37.9 \%)$ reported moderate-to-high worse disease activity per ception due to routine care delay, and $31.1 \%$ self-reported a disease flare (median RAPID3 score 3.8; IQR 2.0, 5.4). One hundred one patients $(46.1 \%$ ) had high disease activity, while only $15.1 \%$ were in remission. In logistic regression, active disease was significantly associated with delay of scheduled routine care visit independent of disease duration, time from last rheumatology assessment, therapy with b/tsDMARDs, and compliance (Table 1, Figure 1 below).

Table 1.

\begin{tabular}{|c|c|c|c|c|c|c|}
\hline Predictor & $\begin{array}{c}\text { Active } \\
(n=186)\end{array}$ & $\begin{array}{c}\text { Remission } \\
(n=33)\end{array}$ & OR & P-value & $\begin{array}{l}95 \% \mathrm{Cl} \\
\text { Inf. }\end{array}$ & $\begin{array}{l}95 \% \mathrm{Cl} \\
\text { Sup. }\end{array}$ \\
\hline Routine care delay (yes vs no) & $113(60.8 \%)$ & $12(36.4 \%)$ & .030 & 2.459 & 1.091 & 5.543 \\
\hline Disease duration (years) & $\begin{array}{c}10 \\
(4.0,20.0)\end{array}$ & $\begin{array}{c}10.5 \\
(7.0,19.8)\end{array}$ & .695 & 1.007 & .972 & 1.044 \\
\hline $\begin{array}{l}\text { Time since last rheumatology } \\
\text { assessment (days) }\end{array}$ & $\begin{array}{c}68.4 \\
(66.8,75.8)\end{array}$ & $\begin{array}{c}71.2 \\
(66.9,74.9)\end{array}$ & .854 & 1.002 & .978 & 1.027 \\
\hline b/tsDMARDs (yes vs no) & $\begin{array}{c}105 \\
(56.5 \%)\end{array}$ & $\begin{array}{c}15 \\
(45.5 \%)\end{array}$ & .653 & 1.202 & .538 & 2.687 \\
\hline $\begin{array}{l}\text { I-CPR5 (likely low vs likely high } \\
\text { adherent) }\end{array}$ & $\begin{array}{c}36 \\
(19.4 \%)\end{array}$ & $\begin{array}{c}10 \\
(30.3 \%)\end{array}$ & .187 & .563 & .240 & 1.321 \\
\hline
\end{tabular}

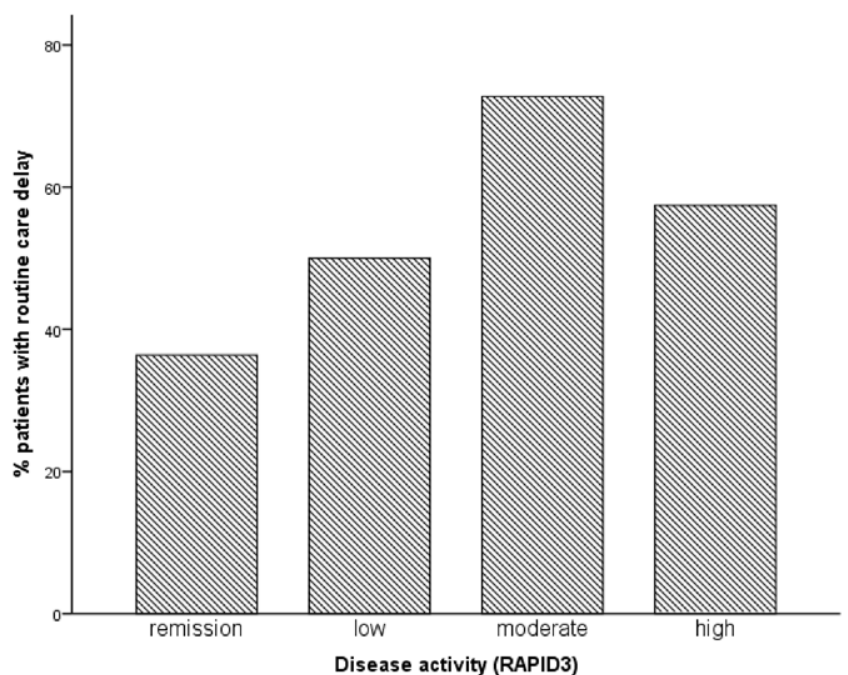

Figure 1.

Conclusion: In patients with established $\mathrm{ClAs}$, a relatively short delay in routine assessment by a rheumatologist resulted in higher disease activity. Frequent rheumatology referrals appear to be a critical factor for disease activity control in CIAs. Disclosure of Interests: None declared.

DOI: 10.1136/annrheumdis-2021-eular.737

\section{POS1174 HYPERINFLAMMATION AND CLINICAL OUTCOMES FOR PATIENTS WITH SYSTEMIC RHEUMATIC DISEASES HOSPITALIZED FOR COVID-19: A COMPARATIVE COHORT STUDY}

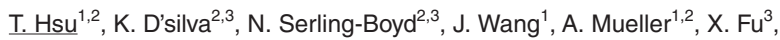
L. Prisco ${ }^{1}$, L. Martin ${ }^{1}$, K. Vanni ${ }^{1}$, A. Zaccardelli ${ }^{1}$, C. Cook $^{3}$, H. Choi ${ }^{2,3}$, Y. Zhang ${ }^{2,3}$, E. Gravallese ${ }^{1,2}$, Z. Wallace ${ }^{2,3}$, J. Sparks ${ }^{1,2} .{ }^{1}$ Brigham and Women's Hospital, Division of Rheumatology, Inflammation, and Immunity, Boston, United States of America; ${ }^{2}$ Harvard Medical School, Division of Rheumatology, Inflammation, and Immunity, Boston, United States of America; ${ }^{3}$ Massachusetts General Hospital, Division of Rheumatology, Allergy, and Immunology, Boston, United States of America 